\title{
Indigenous Wisdom, Capital, Technology and Education
}

\author{
Damian Ruth ${ }^{1}$ iD
}

Received: 21 June 2020 / Accepted: 24 October 2020 / Published online: 31 October 2020

(c) New Zealand Association for Research in Education 2020

\begin{abstract}
This article contrasts specific aspects of indigenous world views and wisdom on the one hand with specific themes in capitalism, colonisation, corporate interests, technology and education, on the other and argues that there is a fundamental clash of values between them. There is no assumption of a homogenous indigenous wisdom and no claim is made about novel insight into capitalism, colonisation, corporate interests and technology and education. The contribution is in tracing lines of thought in all of them and, by juxtaposing them in the context of a contemporary upsurge in digital/online/blended learning with particular attention to the global techno-corporation, to expose a fundamental clash of values that deserves more thorough scrutiny than it is getting. The paper does not present a linear argument, but rather a woven tapestry of themes. The conclusion is that education would be better served by the insights of indigenous wisdom and a more critical and tempered view of capitalism and technology.
\end{abstract}

Keywords Indigenous wisdom $\cdot$ Capitalism $\cdot$ Technology $\cdot$ Educational technology

\section{Introduction}

When Mäori hunters returned from the forest with birds they had killed, they gave a portion of the kill to the priests, who, in turn, cooked the birds at a sacred fire. The priests ate a few of them and then prepared a sort of talisman, the mauri, which is the physical embodiment of the forest hau which translates from the Te Reo as 'spirit,'. This mauri is a gift the priests give back to the forest and which "causes the birds to be abundant. ${ }^{1}$

\footnotetext{
${ }^{1}$ Hyde (1972, p. 18) points that there are three gifts in this hunting ritual: the forest gives to the hunters, the hunters to the priests, and the priests to the forest. Without the priests there is a danger that the motion of the gift will be lost and that the ritual becomes a simple give-and-take, and the hunters may begin to think of the forest as a place to turn a profit.
}

Damian Ruth

d.w.ruth@massey.ac.nz

1 Massey University, Palmerston North, New Zealand 
It is estimated that American settlers slaughtered between 30 to 60 million bison in the 19th Century. Hunters on cross-country trains would shoot bison from their windows, sometimes several at a time. They would then often cut out the tongues and leave the rest of the carcass to rot. ${ }^{2}$

This paper explores the clash between a sensibility shaped by indigenous world views on the one hand and capitalist/marketized world views and a technological mindset on the other. It identifies a core of sensibilities among many indigenous peoples without assuming a homogenous indigenous world view and it does not attempt to convey the complexities of indigenous wisdom. It identifies capitalist/marketized world views and relates them to colonisation. It then identifies specific themes in technology, particularly educational technology. The paper does not offer comprehensive or novel insights in these fields. Rather the contribution is in tracing lines of thought in all of them and, by juxtaposing them in the context of a contemporary surge in digital/online/blended learning, illuminate a fundamental clash of values that deserves scrutiny. The reader is invited to consider the metaphor of plaiting, or, since I am writing in Aotearoa New Zealand, rauru, a te reo word, one meaning of which is plaiting strands to form a cord but which has other relevant meanings.

There is some urgency to the debate as COVID-19 takes its toll and educational institutions in Aotearoa New Zealand as elsewhere turn to distance and online learning as a kind of saviour. In doing so, some pitfalls of educational technology are being glossed. COVID-19 presents an opportunity for the shock troops of capitalism (Klein, 2007, 2020) from the level of the individual entrepreneur (Subramanian, 2020) to the giants of corporate technology (Microsoft teams, fb, etc.). The combination of capitalism, colonial legacies, corporate power and technology create a toxic brew that stands in radical contrast to the need for environmental sustainability and what indigenous wisdom has to offer. The intention here is to refine and advance the arguments about the deleterious effects of education-as-market (Ruth 2018) in combination with the critical analysis of Māori and technology (Marshall 2000). Ruth offers a view of education as gift, a sustainable cyclical process which stands in contrast to the unsustainable extraction of commodity exchange value where education is a commodity and the student a customer. Marshall's critique of the introduction of technology as a school subject in New Zealand in 1993 invokes Heidegger's concept of standing reserve in which everything, including humanity, is turned into an exploitable resource. Heidegger's view of the non-neutrality of technology and its exploitative nature resonates with the indigenous view of the interconnectedness of things. The implication of Ruth and Marshall's positions is that the world of capitaliszed, marketized and technologized education is incommensurate with an indigenous view of education as a process of developing a holistic awareness of being

\footnotetext{
${ }^{2}$ The slaughter of bison was connected to the intended extermination of the Native Americans, and it continues today putting the remaining small herds in Yellowstone at risk. It is now called hazing, relocation or wildlife management but "it is really the continuation of a senseless path forward, driven by greed, profit, and the demand for cheap hamburgers". Buffalo Field Campaign (https://www.buffalofie ldcampaign.org/ accessed 21 May 2020).
} 
in and part of the world, a sensibility, or worldview, eloquently describe by Mason Durie, Charles Royal, Carl Mika, Georgina Stewart and others.

Because the organizational logic of the paper is that of weaving, tapestry or plaiting, rather than a linear sequence of points, I offer at this point an overview. The first strand is indigenous wisdom, with an emphasis on Māori epistemology. The second strand is some core features of capitalism. I then return to broader points of indigenous wisdom. This then allows for the consideration of colonisation. The next major strand is technology. We then return again to indigenous epistemology. We are then able to consider capitalism with particular reference to the corporation. This combination is particularly pernicious in terms of education, where the thrall of technology may obscure the extent of marketization and corporatization in education via 'tech giants'. We then move on to the technologized mindset followed by a specific consideration of educational technology. The intent is to develop the case that the summative impact of the world view informed by capital + market + corporation + technology is much greater than its parts, and in its effect, and in contrast to an indigenous perspective, is inimical to the well-being of the earth and all in it. Hence throughout the paper the constant references back and forth and across the different strands. It seems appropriate that a paper challenging the dominance of a Western mindset that assumes that atomising and disassembling phenomena is an unproblematic and productive way of understanding, and that linear logic is preferable to a circular or spiralling approach, adopts the latter approach.

\section{The Challenge of Contrasting 'Indigenous' and 'Western' Wisdom}

Defining 'indigenous' is politicaly fraught. The term has been politically useful, but it tends to 'normalize diverse groups' (Mika 2016) so I shall outline characteristics rather than offer a definition, which also better suits the paper's theme. Contrasting indigenous and Western wisdom can be misleading. Bird-hunting Māori and bisonhunting settlers were not doing the same thing but nor were the bison-hunting settlers doing what their forebears did. Watson (2005, p. 135) in the context of world history points out that "in many cultures, the first few seeds are not sown but thrown down alongside the furrow as an offering to the gods. By the same token, the last few fruits were never taken from the tree, a few tufts of wool were always left on the sheep and the farmer, when drawing water from the well, would always put back a few drops so that it would not dry up". Hyde writes in the context of reciprocity and gift. His thinking aligns with Sandel's (2007) case against the pursuit of perfection which celebrates the market and technology but ignores the giftedness of life. Here lies the clash between a groundedness and mutual recognition endemic to indigenous sensibilities and the everywhere no-place of global neo-liberal capitalism and the disembodied virtual presentation of personhood.

Wisdom has become an explicit concern in management (Kessler and Bailey 2007; Kupers and Pauleen 2013) which behoves those concerned with management and especially the management of education to emerge from the pit of economic managerialism, raise their sights higher than the current year's budget, and become aware of the culturally specific and dominant norms prevailing in their practice 
(Fitzgibbons and Humphries 2011; Henry and Pene 2001). Let us bear in mind the contrast between the bird hunting of Māori in Aotearoa/New Zealand and the bison hunting of the American settlers. The contrast demonstrates fundamental differences about being in the world, and different understandings about what the world is and how we may know it. Some general distinctions may sometimes be made between Western science and indigenous knowledge, but they are always problematic. "Indigenous knowledge cannot be verified by scientific criteria nor can science be adequately assessed according the tenets of indigenous knowledge. Each is built on distinctive philosophy, methodologies and criteria" (Durie 2005, p. 1). Furthermore, in making such distinctions, the fundamental debates within and the crituqes of western science (Casti 1989, 2001) are too easily elided. Likewise, one may challenge beliefs surrounding indigenous knowledges but although beliefs such as " (a) knowledge can be neatly divided into indigenous versus Western worldviews, and these epistemologies are opposite and irreconcilable, (b) indigenous knowledge always supports a view of nature and of social life that is inherently benign and based on an ethic of care, and (c) indigenous knowledge is static and immutable, and when indigenous youth adopt ideas or practice exogenous to the culture they lose their sense of identity" (Barca and Arenas 2012, p. 5) may be challenged, it is the case that indigenous communities can find common ground on the basis of a human-ecological union with a distinctive environmental ethic (Durie 2005, p. 302).

Although one may write of indigenous without falling into Othering and homogenizing (Royal 2004), the process of Othering and homogenizing usually entails epistemic and cultural violence. 'Indigenous' is at best "a placeholder for diverse specific traditions that are localised and place based, unlike each other but sharing a philosophical base..." (Stewart 2020, p. 39). The emphasis in many indigenous authors is on the relationship with the environment. More specifically, 'a "formal indigenous culture" is one that is conscious in its relationship with natural world environments' (Royal 2004, p. 1, emphasis in the original). The tendency to associate 'indigenous' with a group of people is misleading. It is rather a worldview and set of values. It is "a way of seeing, being, thinking and experiencing the world" (Royal 2005, p.6). In terms of knowledge, it involves internalised knowing, knowing of the head and heart, an understanding, illumination, and wisdom (Royal 2005).

\section{Capitalism and Markets}

At this point we may note the following intersections with capital. In terms of capital, we have reached a point of the market mind. Post the 2008 GFC, Chang (2010) wrote of 23 things that needed to be said about capitalism. The thrust of his argument is that the neo-liberal ideology of free markets is not capitalism but destroys it. There is no such thing as a free market. Debates about free and fair trade are "essentially about moral values and political decisions ... it is not something economists with their technical tool kits are particularly well equipped to rule on" (Chang 2010, p. 7). What is required is an assessment of foundational values. Chang does not, in his critique of the capitalist system, dismiss the profit motive, but there is an important nuance here. Profit-seeking is not greed, and 'the fateful change that unfolded 
during the past three decades was not an increase in greed. It was the expansion of markets and of market values, into spheres of life where they don't belong... we need to ask whether there are some things money should not buy" (Sandel 2012, p. 7). How to value health, education, family life, nature, art, civic duties are, Sandel insists, moral and political questions. Of course, the environment and education can be capitalized, marketized, financialized, but this does not simply clash with an indigenous world view, it destroys it, along with a concept of education connected to human flourishing. The crux of the issue is the very concept of value, and how we distinguish between creation and extraction, between productive and non-productive activities. In the words of Mazzucato (2018) how do we establish the value of everything and analyse making and taking in the global economy. The dominant current world view marked by concepts of capital and market is predicated on fragmentation, alienation and extraction, and given the state of the earth, is manifestly bankrupt. This view contrasts starkly with indigenous knowledge. I have invoked the metaphor of rauru, of plaiting. I am not Māori and do not speak te reo, but the little I have learnt so far leads me to appreciate what an intensely contextual and associative language it is. Rauru is plaiting but also refers to the umbilical cord. This sense of an interconnected, integrated and ecologically sensitive connection with mother earth and one another is a thread running through Chang, Sandel and Mazzucato's arguments.

\section{Some Distinguishing Features of Indigenous Wisdom}

As noted above, to write of indigenous runs the risk of misleading homogenization. I do not assume sameness, but pointing out certain sensibilities common to indigenous peoples from different parts of the world help to highlight the deficiencies in the capitalist-techno-global mindset. According to Viergever (1999, in Durie, p. 3 ) the three distinguishing features of indigenous knowledge are "that it is a product of a dynamic system, it is an integral part of the physical and social environment of communities and it is a collective good The emphasis on the ground, the earth, the environment is repeatedly emphasized in indigenous knowledge relating to "a specific local environment over the long term ... settling in and sinking one's roots" (Jolly et al. 2011). The sense of contextual time as opposed to clock time is noted (Verbos et al. 2011). Whereas breaking down into component parts is standard Western scientific method, "indigenous knowledge places greater emphasis on the construction of models where multiple strands can be accommodated to make up an interacting whole. Understanding comes not so much from an appreciation of component parts as from synthesis into a wider context" (Durie 2005, p. 5).

These themes are noted by indigenous intellectuals from different parts of the world. Gregory Cayete, Tewa of New Mexico, describes traditional American Indian education as an education that "sustained a wholesome life process ... that unfolded through mutual, reciprocal relationships between one's social group and the natural world ... a communally integrated expression of environmental education. ... emphasizing how our lives are truly and profoundly connected to other people and the physical world (1994, pp. 26-27). Senghor (in Shutte 1993, pp. 25-26), on 
African knowing writes... the Negro African does not draw a line between himself and the object; he does not hold it at a distance ... his participation is intuitive". In recent decades, especially through East and Southern Africa, the concept of Ubuntu has developed (Bhengu 1996; Mbigi and Maree 1995; Boon 1996; Qobo and Nyathi 2016). It is a humanistic philosophy expressed through the proverb "a person is a person through other people" and emphasizes the relatedness of all people and of all people with nature. It emphasizes the collective and solidarity, the connection with the land and nature, and a sense of service and stewardship.

However, in terms of education, the challenge is substantial. Altbach (1982) points out that it is not easy to create 'indigenous' academic models because the institutional patterns and the pedagogical techniques and even the basic structure of knowledge prevalent in universities today are Western in origin. They are encoded with a specific logos and Anthropos, that hang together (Eze 1997, p. 13). Henry and Pene (2001, p. 239) also note that "for Māori the western university is as problematic as the knowledge it constructs" and they explain how whare wananga which means houses of higher learning have been developed to counter the "epistemic violence' inflicted by Eurocentric epistemologies (Seuffert 1997). I continue to explore indigenous, specifically Māori, values below, but this is an appropriate point to note the importance of "a specific local environment over the long term ... settling in and sinking one's roots" and the metaphor of rauru. Indigeneity is "predominantly a Western idea in its essence" (Mika 2016). Indigenous peoples have no need to define themselves as indigenous - it only made sense to do so in the face of a coloniser. It was capital seeking resources and markets in 'foreign' lands that created 'indigenous' and supported the cultural complex of fascination with the exotic, along with appreciation, insult, contempt and eventually degradation and exploitation. I return to the matter of epistemic violence and an attention economy below. We now turn to connect the above themes to technology.

\section{Technology}

In the myths of humans getting power and knowledge, warnings, prohibitions and caveats abound. We may enjoy the gifts of technology but should note the violence and loss the gifts entail (Burnett et al. 2009). Furthermore, the impact of a new technology is often quite subtle and slow, but far-reaching. For example, the introduction of the heavy plough in the Frankish Empire radically reversed the relation between man and nature by making the capacity of a machine, rather than human need the standard of land division. "Formerly he had been part of nature; now he became an exploiter of nature" (White 1971, pp. 172-173). This reversal burgeoned into the scientific method.

The controversy over Francis Bacon's torturing of nature or putting her on the rack, is complex (Pesic 1999) and beyond this paper, although there is a point to be made here about the conflation of Other with reference to the white male, in which nature and indigenous/brown/black/female are treated as subordinate with man (sic) as scientist is engaged in heroic struggle with nature in which both are tested and purified. It is not a relationship predicated on assumptions of interconnectedness. 
Pesic suggests that Bacon's vocation as a lawyer and judge relates to his use of "torture" (or its Latin cognates) to denote excessive and wrongful force; he never speaks of experiment expressly as the "torture of nature." In contrast, he uses "vexation" to indicate agitation or disturbance within legitimate limits. We will return to the language of vexation and torture below. Despite Pesic's defence, the feminist critiques of 'heroic' 'testing' and 'purification' stand.

In identifying technique, or technical efficiency, as the key ideological fetish of modern industrialized authoritarian states, Marcuse (1941, p. 138) defined technology as "a mode of production, as the totality of instruments, devices and contrivances which characterise the machine age [which] is thus at the same time a mode of organizing and perpetuating (or changing) social relationships, a manifestation of prevalent thought and behaviour patterns, an instrument for control and domination". In this state "the efficient individual is the one whose performance is an action only insofar as it is the proper reaction to the objective requirements of the apparatus, and his liberty is confined to the selection of the most adequate means for reaching goals which he did not set" (p. 142). Rationality is transformed from being a critical force into one of adjustment and compliance. In a technological society, the structure of all human life and its systems of organization reflect the logic of the machine (Ellul 1973). The implications for education are obvious. The point of tertiary education, we are constantly told, is to produce 'work-ready graduates'. Given how the economy in most developed/Western countries is stacked against the marginalised indigenous (and female) population, being 'work-ready' may provide for individual escape as it promotes the uncritical social reinforcement of disadvantage.

\section{Indigenous Wisdoms}

We now turn back to some core features of indigenous views, particularly Māori world views, before returning to a closer examination of capital and markets. The core Māori value of being-in the-world as relational wisdom rests on kaitiakitanga or stewardship through which humans as stewards are endowed with a mandate to use the agency of their mana (spiritual power, authority) to create mauri ora (conscious well-being in a web of reciprocal relationships. In the Māori view, a human is born into a relational world as kaitiaki, empowered to be a steward and endowed with obligations. It creates a sense of belonging, a kinship which is an expansive term for a variety of relationships. (Spilleret al. 2011a, b, p. 226). These values exist in dynamic relationship to one another as interlocking parts of a whole system of knowledge and are inseparable from the ongoing context of life itself. The environment itself is a stakeholder. Who speaks for the trees? This question is core to indigenous culture and to sustainable development. Spiller et al. offer a comparison of 'unwise' and 'wise' organizations in terms of Māori wisdom. It is worth expanding on the idea of mana in the light of what has been observed about technology. In the Māori worldview, the child arrives with mana, and agency to create mauri ora, a conscious well-being which is the well-spring of sustainability. Mana as a concept denotes agency for realizing potential. Mana means spiritual power, authority, and sovereignty, drawn from various sources. Being a steward endowed with mana 
requires that a child lives, and grows into an adult, in respectful recognition of their own mana and mana in the world around them. In this view, empathetic relationships are not limited to a parental figure alone but include spiritual, ancestral, environmental, as well as human emotional attachments. These reciprocal relationships of respect appreciate that personal well-being is intimately linked to the well-being of others and the environment. It is an ethic that seeks to uplift and empower others for the common good which is threaded into the fabric of existence (Henare 1998, p. 18). In explaining relational well-being, wealth and an ethic of care in terms of business, Spiller et al. (2011a, b) contrast Māori values with independent, rational, self-interested, utility maximizing organizations and individuals. Their analyses correlate with differences between Native American and dominant values in management education tabulated by Verbos et al. (2011).

\section{Capital, the Corporation and Technology-Mergers Made in Hell}

The core of capitalist ideology is the idea of independent, rational, self-interested, utility-maximizing organizations and individuals. Management education often deteriorates into a celebration of this ethos and under the influence of neo-liberalism the whole of education becomes predicated upon it and violence becomes more comprehensive than epistemic (Berdayes and Murphy 2016; Choi 2016).

There is an argument in both the marketization and technologization of education that progresses as follows. At some point, it becomes possible to place a market value on something. We can put a price on it - a field of wheat, the machine, a person. We may turn a process or insight into intellectual property. In this way we convert one thing into something else. A person becomes a slave, or a unit of labour, calculable in money. At first there is doubt which may become a hue and cry and the tensions are explicit. But the conceptual process proceeds: it is possible to monetize/ technologize something; it is possible to monetize/technologize almost anything; the monetized/technologized form is what is valued; therefore, if we want to value something, we should monetize/technologize it; there are advantages to monetization/technologization; therefore we should monetize/technologize all possible things so that they can be valued; eventually, only those things which can be monetized/ technologized can and will be valued. The market shall be joined with technology and together they shall govern. The conditions, languages, entities, and values that prove recalcitrant will be relabelled, which will lead to redefinition and possibly eradication. When digitalization, even in the euphemistically and wholesomely labelled 'blended learning' environment meshes with the power of giant technology corporations, the need for vigilance becomes a matter of democratic survival and social justice.

The corporation has a profit-seeking logic. As universities become corporatized and technologized there is an exponential impact. We need to appreciate that the technology of computers, virtual lecture theatres, Skype, Zoom and so on is not the whole picture of technology. The artefacts and the processes we create to use them eventually create their own mindset. When we talk about distance learning, or online courses, we are not simply appending an adjective to an artefact, we are 
changing what we mean by 'learning' or 'course'. It is an ecological change. Likewise, when profit becomes the institutional goal, this goal begins to shape individual actions. Fiscal efficiency rather than social benefit begins to shape the intellectual landscape of teachers, lecturers and students. Using a machine to efficiently process an investment is not the same as educating a person; the corporatized technologized university (if it still makes sense to call the machine that) does the former. It does not do the latter.

Klein (2020, p. 38) noting how Eric Schmidt of Google celebrates "The ad hoc home schooling programme that teachers and families across the country had been forced to cobble together during this public health emergency as 'a massive experiment in remote learning" "warns of education, health and society at large saturated with corporate interest. The crux here is intent and this is the brilliant Heideggerian insight of Kubrick's 2001 Space Odyssey, when from one second to the next a bone becomes a spaceship. We should not gloss artefact and intent. A bone is a bone until it is used as a weapon; it is not made as such. A nuclear weapons satellite is made as a weapon. That technology may not create intent does not mean that its deployment is neutral (cf Marshall on Heidegger above). It is always ideological, and the story of technology is not only a story of incremental improvement. It is a story of radical ecological change. The train and rifle were not the cause of settler avarice but they radically facilitated the process of extraction (tongues for the plates of wealthy Easterners), destruction and waste.

What must be emphasized here is the role of the corporation as "an autonomous technical structure that behaves by a system of logic uniquely well suited to its primary function: to give birth and impetus to profitable new technological forms, and to spread techno-logic around the globe" (Mander 1991, p. 120). There are, according to Mander, eleven inherent rules of corporate behaviour: the profit imperative; the growth imperative; competition and aggression; amorality; hierarchy; quantification, linearity, and segmentation; dehumanisation; exploitation; ephemerality; opposition to nature, and homogenisation, and "to ask corporations to behave otherwise is like asking an army to adopt pacifism. Form is content” (p. 137). Achbar and Abbot (2003) diagnose the corporation as a psychopath. This presumes an identity imbued with intent and thereby brings into question the notion of 'person'. How do we respond in the face of what corporations do? Are they simply diseased and therefore requiring treatment? Have we reached a point of necessary euthanasia for the common good? Corporations are major producers and consumers of technology and the quintessential means of this process is the computer. With this perspective, we could understand better the limits of the computer revolution. "If the triumph of a revolution is to be measured in terms of the social revision it entrained, then there has been no computer revolution" (Weizenbaum 1976, p. 32). Postman suggest that if Riesman was right in calling the press "the gunpowder of the mind", the computer, "in its capacity to smooth over unsatisfactory institutions and ideas, is the talcum powder of the mind" (Postman 1993, p. 116). Forty years later, we could say the same of the digital 'revolution' and the inherent criminality of the corporation (Tombs and Whyte 2015). Foer (2017, p. 55) finds it "chilling to hear [Larry Page] contemplate how Google will some day employ more than one million people ... that's not just dominating an industry ... it's a statement of Google's intent to 
impose its values and theological convictions on the world..." He notes that "Facebook is a carefully managed top down system, not a robust public square ... a tangle of rules and procedures for sorting information, rules devised by the corporation for the ultimate benefit of the corporation" (p. 57). Facebook creates the impression it offers choice as it paternalistically nudges users in the direction that thoroughly addicts them. It is a massive deceit. He notes computer scientists' aphorism that describes "how algorithms relentlessly hunt for patterns: they talk about torturing the data until it confesses... Data, like victims of torture, tells its interrogator what it wants to hear ... When we outsource thinking to machines, we are really outsourcing thinking to the organization that runs the machines" (p. 72). The computer scientist torturing the data in order to create algorithms that will in turn control users is Baconian par excellence. I now turn back to technology per se for a moment, before turning to technology in education.

\section{Technology}

Postman opens his essay on technology with reference to the legend of Thamus who challenged the god Theuth with his many inventions, one of them being writing. Thamus duly assesses the gift and points out that although it may confer advantages, it is not a tool to increase wisdom, but merely a tool for recollection. Postman makes the point that "The discoverer of an art is not the best judge of the good or harm which will accrue to those who practice it" (Postman 1993, p. 4). We should beware of "zealous Theuths, one-eyed prophets who see only what new technologies can do and are incapable of imagining what they will undo" (p. 5). Technology changes our language, our words, and then our discourse, and then our thinking. It creates new definitions of old terms and "imperiously commandeers our most important terminology". Technology is not an equalising instrument. It confers status and power and the benefits and deficits of a new technology are not distributed equally. "Embedded in every tool is an ideological bias, a predisposition to construct the world as one thing rather than another, to value one thing over another, to amplify one sense or skill or attitude more loudly than another" Postman points out (p. 13) and notes that "New technologies alter the structure of our interests; the things we think about. They alter the character of our symbols; the things we think with. And they alter the nature of community: the arena in which thoughts develop" (p. 20).

Odell (2019) writes of resisting the attention economy, and refuses "the frame of reference in which value is determined by productivity, the strength of one's career, and individual entrepreneurship [and wishes to celebrate] a form of the self that changes over time, exceeds algorithmic description, and whose identity doesn't always stop at the boundary of the individual" (p. xvi). It means paying attention or concentrating. Her focus on attention goes to the heart of education. Technology that is episodic and manipulative runs counter to an education that seeks to enable deep sustained awareness and analysis. The attention economy relies on fear and anxiety, with the assumption that disruption is more productive than the work of maintenance. Capitalist logic thrives on myopia and dissatisfaction-we inhabit a culture that privileges novelty and growth over the cyclical and the regenerative. (p. 
25). Odell's thinking resonates with the local, rooted, temporal nature of indigenous wisdom. The issue here is "context collapse" which creates a "lowest-commondenominator philosophy of sharing [that] limits users to topics that are safe for all possible readers." (Marwick and Boyd 2011, p. 126, in Odell p. 159). Spatial context collapse (Meyrowitz 1986) is accompanied by temporal collapse, into what Odell describes as "one big "situation," [wherein] instantaneity flattens past, present and future into a constant, amnesiac present. The order of events, so important for understanding anything, gets drowned out by a constant alarm bell" (p. 163).

Carr (2011) too is worried about what the internet is doing to our brains. Like HAL at the end of 2001 Space Odyssey he feels "my mind is going, I can feel it. I can feel it". Carr feels that the net is "chipping away at my capacity for concentration and contemplation" (p. 6). Print allowed us to become deep readers and ponder meaning. With screen and social media we can still decode text quickly, "but we are no longer guided toward a deep, personally constructed understanding of the texts' connotations. Instead we are hurried off toward another bit of related information, and then another and then another. The strip-mining of 'relevant content' replaces the slow excavation of meaning" (p. 166). Strip mining captures the essence of the settler/capitalist view of the world. It is non-ecological. In Google's world, intelligence is equated with data-processing efficiency, the brain is a big chip in the skull, it can solve vastly complex problems that have never been solved before, but cannot assess what problems are worth solving, and ambiguity is not an opening for insight, but a bug to be fixed. (Carr, p. 73). Commenting on the backlash to The Shallows Carr records that he has dozens of stories from people on how the Web "has scattered their attention, parched their memory, or turned them into compulsive nibblers of info snacks". There is a massive deceit at play, whereby acquisition of information masquerades as understanding.

Technology is a mindset that has a specific production logic (Franklin 1990/1999). The crucial idea in terms of education is the distinction between what Franklin calls holistic technologies and prescriptive technologies. The focus is not on what is being done but how it is done. In holistic technologies the doer is also the planner and is in charge of the process and decision-making throughout, whereas prescriptive technologies entail a division of labour designed for compliance. Prescriptive technologies are underpinned by a production model. Those areas of human activity related to caring, and that require reciprocity, such as education, nursing and all the caring professions, are intensely relational and contextual. We have become so used to production models that although we might accept that students, patients, the frail and the aged cannot be effectively cared for if they are considered as material objects, we continue to design systems as if they are.

An important feature of production models that Franklin points out is that it easy to frame the process to allow for externalities to be disregarded. "Production models are perceived and constructed without links into a larger context. This allows the use of a particular model in a variety of situations. At the same time such an approach discounts and disregards all effects arising from the impact of the production activity on its surroundings... We know today ... that the deterioration of the world's environment arose precisely from such inadequate modelling. Processes that are cheap in the marketplace are often wasteful and harmful in the larger context, 
and production models make it quite easy to consider contextual factors as irrelevant (pp. 20-21). As wtih Odell and Carr the clash with an indigenous world view is clear. In a world where everything is connected and we are all part of a woven fabric, there are no externalities. Environmental feedback is part of what is being done. Franklin links this to education.

What is disregarded in the production model of education is ... "an individual's own conscience and discernment" (p. 37). The development of an individual's conscience and discernment is precisely the goal of education. Crucial to education would be presence and reciprocity, which, Franklin stresses, is not feedback. "Feedback is a particular technique of systems adjustment ... [it] exists within a given design. It can improve the performance, but it cannot alter its thrust or the design. Reciprocity, on the other hand, is situationally based. It's a response to a given situation. It is neither designed into the system nor is it predictable. Reciprocal responses may indeed alter initial assumptions. They can lead to negotiations, to give and take, to adjustment, and they may result in new and unforeseen developments" (p. 43). Feedback masquerading as reciprocity is a deception, a lie. A non-negotiable nonreciprocal predictable 'education' is training of the lowest order, akin to training rats.

\section{Technology in Education}

Technology as saviour in the face of calamity is not new in education, but there are several reasons to be cautious. This is not the first-time educators have turned to digital technology in times of crisis (Czerniewicz 2020). It happened with the Christchurch earthquake, the New Orleans floods, political unrest in Hong Kong and many times in South Africa. In such circumstances the variations of blended learning get "drawn in existing political agendas and extreme claims [are] made. Conspiracies flourish ... fake news will infiltrate the system ... technological decisions will be shaped in ways that reflect existing differences, alliances, discourses and perspectives in particular institutions ... hurried incomplete efforts to teach online give blended learning a bad name". Czerniewicz notes that teams working in digitally mediated education literacies depended on face-to-face team interaction for collegial support. She concludes that threaded through the debates are "questions of power and whose interests are being served ... it will be political ... change will be appropriated for different ends and tell different stories for different people. Technology is never neutral".

A general point made by many negative critiques of educational technologies is that they replicate, reify and support existing political, economic and social relations and in this respect their innovativeness is limited. They tend towards intensification, standardisation and homogenisation. The promise of greater freedom and flexibility is false - the truth is that most of these technologies are reductionist. A virtual world is better described as a "synthetic" (Castronova 2006) world, or "simulacrum" (Murphy 2012). The virtual classroom is a "non-place" (Auge 1995). In such environments the participants do not have the power to influence or modify the terms of engagement. They offer what Fuery (2008, p. 33) call a "false mode of 
active engagement". There are multiple dimensions of falsehood. That which seems to matter most in effective teaching-professionalism, a sense of vocation, emotion and embodiment and interpersonal relationship, is diminished. What takes place is not "collaborative collegiality, but interaction between teachers that are coerced, administratively regulated and orientated around the implementation of predetermined outcomes" (Selwyn 2014, p. 60).

In terms of open technologies Selwyn notes tensions between individual and collective production, power imbalances in production processes, and that the mass consumption of open courses does not alter the state of an elite remaining the processors. As Jeremy Knox (2012, in Selwyn, p. 80) has noted, the limitations of production and consumption are evident in the emphasis of open educational resources on individual self-driven-direction and autonomy. Open access does not alter the basic revenue model of capitalist societies. There are some analysts who perceive benefits to digital games, but again Selwyn offers a persuasive list of reservations which cohere around how such games reinforce individualism, possessiveness and competition, and that the "learning" in digital games "supports repetitive adjustments to the rules, rhythms and expectations of the game design rather than genuine educational engagement" (p. 104). Social media seems to promise change opportunity. However, popular criticism abounds. Social media does not promote independent and critical thought, distracts from learning, and promotes disrespectfulness. And as Selwyn points out most social media are not actually especially participatory in nature. Most applications rely on a small core of producers and promote consumption as a greater value than production. They rely on an ambivalent consumer who always wants more and are linked to commercial and corporate interest. Social media creates an affective economy requiring constant self-valorisation, bounded by an attention economy, "compelling users to concentrate on a commoditized promotion of self, as well as the maintenance of personal status, favour and online reputation" (Selwyn, p. 121). Although as social beings we always 'present' ourselves to others, social media ramps up the potential for outright deceit. It also "engenders a particular kind of'sociability' - a safe, non-threatening exchange in where everyone is obliged to 'join' and 'participate' but where actual actions and knowledge are highly conformist and consensual ... dialogue becomes increasingly ritualized and composed solely of mantra and cliché" (p. 121).

We may begin to discern here those elements of technology that inculcate and promote a mechanistic, fragmented, decontextualized and extractive mentality that is at odds with a relational, contextualised and holistic understanding of humans in the world based on reciprocity. Bowers $(2000,2014)$ notes the failure of computer enthusiasts to examine their deep cultural assumptions and the ethnocentric and formulaic quality of their thinking. He points out even the valid criticism of computer-mediated education lacks a global perspective on the world's ecological crisis. "What is missing is how the Western technological mindset differs from that of other culture groups-particularly those that have encoded their knowledge of place, relationships, and life cycles into the mentoring, narrative and ceremonies" (2000, p. 112). The promotion of cheap, just in time learning does not attend to the traditional purposes associated with higher education, specifically "exposure to a broad range of cultural traditions that enable active and reflective participation in civic life" (p. 
19). Computer advocates are too prone to abstract thinking and a "dangerous combination of altruism and romanticism" (p. 122). He repeatedly makes the point, made by many others, that when an institution outsources education to a technology, it is outsourcing it to the corporation that controls the technology. He points out that thinking skills are not culturally neutral. A tool like Storybook Weaver assumes that "culturally autonomous students construct their own understanding of the external world ... [a problem] for a culture that encodes its moral framework in a knowledge of ecological relationships in the narratives that are passed down through generations" (2014, p. 130). He makes a cogent case for how digital technology reinforces abstract thinking and cannot grasp the complexity of local cultural and environmental contexts, which he calls cultural and natural ecologies. Technology reinforces the common but misguided assumption that the point of education is to promote freedom and individual autonomy as though individuals can exist independently of the cultural natural ecology from which they derive their language and basic sources of energy.

\section{Conclusion}

The creation of an educational industry and privatisation, along with digital technology in education, promises much and does indeed deliver some benefits to some, but it also deceives and destroys. Given the theme of clashing values, we should consider the corporation and technology in education as a kind of colonisation. Although not always at the same level of explicit brutal destruction inflicted on indigenous cultures by waves of imperialist colonisation, we should note that schools and 'education' were major tools in the colonial arsenal (McKinley and Smith 2019) and they can become sites of resistance and recovery. The Welsh 'not' was used to punish schoolchildren who spoke Welsh in schools in C19. Today school children have been punished for not speaking Welsh (The Telegraph, 14 November 2012). Māori children were beaten if they spoke te reo. In September 2020 we had, in Aotearoa, Te Wiki o te Reo Māori (Māori language week). The Kenyan author, Ngugi wa Thiongo, educated at a mission school, wrote in Decolonising the Mind (1986) how the colonial classroom became a tool of psychological conquest in Africa and beyond. "Better than the cannon, it made the conquest permanent," he wrote. "The cannon forces the body and the school fascinates the soul." The point here is that education in practice is never a pure enterprise. It is always political, economic and ideological.

Times of transition usually entail the risk of valorising the ideological at the expense of the the philosophical. In the light of COVID-19 a senior university academic in New Zealand wrote of her university's gains in its capacity to provide online learning as "let's not go backward ... the genie of online learning is now out of the bottle ... how do we ensure online learning is seen as good as, if not better than, the traditional on-campus experience?" (Byrnes 2020). Byrnes' comments are frequent themes in the educational technology debate; the novel technology is assumed to be positive; and the genie metaphor alludes to a magical fulfilment of desire. This is the context in which my university has ramped up support for staff 
to teach online with concern for the well-being of educators and students framed in human resource terms and relatively little explicitly political and philosophical debate on the nature of and purpose of education. The techno-genie has been emerging from various vessels ever since a human picked up a bone to bash another human's head. The market entices and technology enthralls. To focus on the benefits of technological at the expense of the philosophical and political is itself a political and ideological manouevre. Intense transitions provoke more than an adjustment of opinion. They may challenge professional identity and require philosophical contemplation and a reassessment of values.

Benade (2017) reflects on "the mental shifts and sometimes painful transitions teachers and leaders are making and experiencing, as they move through uncharted waters, from traditional classroom practices to ones emphasising collaboration, teamwork and the radical de-centring of their personal roles" (p. 2). Why are teachers finding it painful? I think more is at stake than change or uncharted waters, distinct from the radical de-centring of personal roles. After all, an emphasis on collaboration and teamwork is what many teachers aspire to achieve. In fact, I suspect that many teachers (I certainly did) found that traditional notions of education required a practice more akin to crowd control which many found distasteful but endured and ensured because they had to. A more 'open' relationship would allow for what Benade later identifies as crucial- "giving teachers frameworks on which to construct coherent value positions of their own" (p. 7). The same can be said of students and technologically mediated ersatz collaboration.

The sources of pain in educators have been precisely identified by Palmer (1998): "an obsession with educational externals_-including relentless and mindless standardized testing (p. xvii) ... a mindset that cares more about weights and measures more than meaning (p. xxi)"; he offers the simple but profound premise that "good teaching cannot be reduced to technique; good teaching comes from the identity and integrity of the teacher" (pp. 10-11). He writes of "the pain of having my peculiar gift as a teacher crammed into the Procrustean bed of someone else's method and the standard procedures prescribed by it". The crux of the issue is trust which can be correlated with performance (Bryk and Schneider 2004). This is the pain that educators feel-not being trusted to realise their vocation.

When the interests of accountants and technologists dominate my teaching, I suffer from vocational dissonance and I would say that at the moment the sphere of education in societies is pervaded by systemic dissonance, especially in societies marked by colonisation and in multi-cultural societies with marginalised populations. If we identified neo-liberal economics and technology as contemporary forces of colonisation and appreciated indigenous cultures, we would refuse the intrusion of repugnant values that reduce teachers and students to units of exchange and we would refuse the expectation to cope and endure a sense of helplessness and frustration over the deployment of unnecessary and inappropriate technology. Capital and technology are not central to what I wish to achieve as an educator but have been interpolated into the process. The misguided assumption is that my intent to enhance another person's understanding may be made more efficient. However, I know from personal experience that this is often not the case and claims of greater institutional efficiency are often more assumed than examined. The effect is that I am pushed 
further away from my core work-my vocation. Irrespective of personal proclivity we are not required to engage in philosophical debate, but we are required to engage with technology which is often trivial, banal, manipulative and not worthy of attention. Hence the many furtive sotto voce remarks - confessions actually-of colleagues who struggle. Hence much dark humour and rage. It is a painful situation at a personal level. It is also systemically and socially costly, for widespread vocational dissonance is a loss for the society as whole. In a multi-cultural society, which increasingly means most societies, the epistemic violence of corporate-backed technopoly is a recipe for at least cultural pain and dissonance, if not annihilation. The pain radiates between individuals, cultures and societies via educational systems. The point is:

Tips, tricks and techniques are not at the heart of education - fire is. I mean finding light in the darkness, staying warm in the cold world, avoiding being burned if you can, and knowing what brings healing if you cannot. That is the knowledge that our students really want, and that is the knowledge we owe them. Not merely the facts, not merely the theories, but a deep knowing of what it means to kindle the gift of life in ourselves, in others, and in the world. (Palmer 1998, p. x).

Data can be useful. Wisdom is vital. There is no app for caring.

Acknowledgement I thank Laura Czerniewicz, Jason Mika and Alan Woodside, and the reviewers of NZJES for their helpful comments on drafts of this article.

\section{References}

Achbar, M., \& Abbot, J. (Writers). (2003). The Corporation. In M. Achbar, J. Abbot, \& J. Bakan (Producer). Canada.

Altbach, P. (1982). Higher education in the Third World: Themes and variations. Asia: Maruzen Asia.

Auge, M. (1995). Non-places: Introduction to an anthropology of supermodernity (J. Howe, Trans.). London: Verso.

Barca, D., \& Arenas, A. (2012). Words of caution on indigenous knowledge and education. Educational Practice and Theory, 32(1), 5-28.

Benade. . (2017). Being a teacher in the 21st century: A critical New Zealand research study. Singapore: Springer Nature.

Berdayes, V., \& Murphy, J. W. (Eds.). (2016). Neoliberalism, economic radicalism, and the normalization of violence. Geneva: Springer International Publishing.

Bhengu, M. J. (1996). Ubuntu: The essence of democracy. Cape Town: Novalis Press.

Boon, M. (1996). The African way: The power of interactive leadership. Sandton: Zebra Press.

Bowers, C. A. (2000). Let Them Eat Data: How Computers Affect Education, Cultural Diversity, and the Prospects of Ecological Sustainability. Athens: University of Georgia Press.

Bowers, C. A. (2014). the false promises of the digital revolution: How computers transform education, work, and international development in ways that are ecologically unsustainable. New York: Peter Lang.

Bryk, A., \& Schneider, B. (2004). Trust in schools: A core resource for improvement. Washington: American Sociological Association.

Burnett, J., Senker, P., \& Walker, K. (Eds.). (2009). The myths of technology. New York: Peter Lang.

Byrnes, G. (2020, April). The 'Rosie the Riveter' effect and higher education in New Zealand. Massey News. 
Carr, N. (2011). The shallows: What the internet is doing to our brains. New York: W. W. Norton \& Company.

Casti, J. L. (1989). Paradigms lost. London: Cardinal Sphere Books.

Casti, J. L. (2001). Paradigms regained. New York: Harper Perennial.

Castronova, E. (2006). Synthetic worlds: The business and culture on online games. Chicago: Chicago University Press.

Cayete, G. (1994). Look to the mountain: An ecology of indigenous education. Durango, CO: Kivaki Press.

Chang, H.-J. (2010). 23 things they don't tell you about capitalism. London: Penguin.

Choi, J. M. (2016). Neoliberalism and education: The disfiguration of students. In V. Berdayes \& J. W. Murphy (Eds.), Neoloiberalism, economic radicalism, and the normalization of violence (pp. 27-35). Geneva: Springer International Publishing.

Czerniewicz, L. (2020). What we learnt from 'going online' during university shutdowns in South Africa. PhilOnEdTech (March 15). https://philonedtech.com/what-we-learnt-from-going-online-durin g-university-shutdowns-in-south-africa/.

Durie, M. (2005). indigenous knowledge within a global knowledge system. Higher Education Policy, 18, $301-312$.

Ellul, J. (1973). Propaganda: The formation of men's attitudes. New York: Vintage/Random House.

Eze, E. C. (1997a). Introduction: Philosophy and the (Post)colonial. In E. C. Eze (Ed.), Postcolonial African Philosophy: a critical reader. Oxford: Blackwell.

Fitzgibbons, D. E., \& Humphries, M. (2011). Enhancing the circle of life: Management education and indigenous knowledge. Journal of Management Education, 35(1), 3-7. https://doi. org/10.1177/1052562910392168

Foer, F. (2017). World without mind: The existential threat of big tech. New York: Penguin Press.

Franklin, U. M. (1990/1999). The Real World of Technology (revised edition). Toronto: Anansi Press.

Fuery, K. (2008). New media: Culture and image. London: Routledge.

Henare, M. (1998). Te tangata, te taonga, te ahu: Māori concepts of property. Paper presented at the Conference on Property and the Constitution, Wellington, for the Laws and Institutions in a Bicultural Society Research Project, Waikato University.

Henry, E., \& Pene, H. (2001). Kaupapa Māori: locating indigenous ontology, epistemology and methodology in the academy. Organization, 8(2), 234-242. https://doi.org/10.1177/1350508401082009

Hyde, L. (1972/2006). The Gift: How the Creative Spirit Transforms the World. New York: Random House.

Jolly, F., Whiteman, G., Atkinson, M., \& Radu, I. (2011). Managing and educating outside: A Cree Hunter's perspective on management education. Journal of Management Education, 35(1), 27-50. https ://doi.org/10.1177/1052562910386112

Knox, J. (2012). Five critiques of the open educational resources movement. Retrieved from http://jerem yknox.net/2012/03/28/five-critiques-of-theopen-educational-resources-movement.

Kessler, E. H., \& Bailey, J. R. (Eds.). (2007). Handbook of organizational and managerial wisdom. Los Angeles: Sage.

Klein, N. (2007). The Shock Doctrine: The rise of disaster capitalism. Canada: Random House.

Klein, N. (2020) Click for access in The Weekly Guardian, 29 May, pp. 34-39.

Kupers, W., \& Pauleen, D. (Eds.). (2013). A handbook of practical wisdom: Leadership, organization and integral business practice. London: Gower.

Mander, J. (1991). In the absence of the sacred: The failure of technology and the survival of the Indian Nations. San Francisco: Sierra Book Club.

Marcuse, H. (1941). Some social implication of modern technology. In A. Arato \& E. Gebhardt (Eds.), The essential Frankfurt school reader. Oxford: Basil Blackwell.

Marshall, J. D. (2000). Technology, education and indigenous peoples: The case of Māori. Educational Philosophy and Theory, 32(1), 119-131.

Marwick, A. E., \& Boyd, D. (2011). I tweet honestly, I tweet passionately: Twitter users, context collapse, and the imagined audience. New Media \& Society, 13(1), 114-133.

May, R. (1976). The courage to create. London: Collins.

Mazzucato, M. (2018). The value of everything: Making and taking in the global economy. London: Penguin.

Mbigi, L., \& Maree, J. (1995). Ubuntu: The spirit of African transformation management. Randburg: Knowledge Resources. 
McKinley, E. A., \& Smith, L. T. (2019). Towards Self-Determination in Indigenous Education Research: An Introduction. In E. A. McKinley \& L. T. Smith (Eds.), Handbook of Indigenous Education (pp. 1-15). Singapore: Springer Singapore. https://doi.org/10.1007/978-981-10-3899-0_77.

Meyrowitz, J. (1986). No sense of place: The impact of electronic media on social behavior. New York: Oxford University Press.

Mika, C. (2016). Questions on the Global Indigenous. In M. A. Peters (Ed.), Encyclopedia of Educational Philosophy and Theory: SpringerLink. Retrieved September 18, 2020, from https://link.springer. com/referenceworkentry/10.1007/978-981-287-532-7_509-1.

Murphy, D. (2012). The architecture of failure. Winchester: Zero.

Odell, J. (2019). How to Do Nothing: Resisting the Attention Economy. Brooklyn; London: Melville House.

Palmer, P. J. (1998). Foreword, in Mary Rose O'Reilly The Garden At Night: Burnout and Breakdown in the Teaching Life. Portsmouth, NH: Heinemann.

Pesic, P. (1999). Wrestling with Proteus: Francis Bacon and the "Torture" of Nature. Isis, 90(1), 81-94.

Postman, N. (1993). Technopoly: The surrender of culture to technology. New York: Vintage.

Qobo, M., \& Nyathi, N. (2016). Ubuntu, public policy ethics and tensions in South Africa's foreign policy. South African Journal of International Affairs, 23(4), 421-436.

Royal, C. (2004). Exploring "Indigenous'. Retrieved September 10, 2020, from https://www.charles-royal .nz/papers-reports.

Royal, C. (2005). Exploring indigenous knowledge. Retrieved September 10, 2020, from https://www. charles-royal.nz/papers-reports.

Ruth, D. (2018). Education as gift: Taking education out of the market and the market out of education. New Zealand Sociology, 33(2), 203-228.

Sandel, M. J. (2007). The Case against Perfection: Ethic in the age of genetic engineering. Cambridge, MA/London: The Belknap Press of Harvard University Press.

Sandel, M. J. (2012). What money can't buy: The moral limits of markets. London: Penguin.

Selwyn, N. (2014). Distrusting educational technology: Critical questions for changing times. London: Routledge.

Seuffert, N. (1997). Circumscribing knowledge in Aotearoa/New Zealand: Just Epistemology. [2015]. New Zealand Yearbook of New Zealand Jurisprudence, 1997/7.

Shutte, A. (1993). Philosophy for Africa. Rondebosch: University of Cape Town Press.

Spiller, C., Erakovic, L., Henare, M., \& Pio, E. (2011). Relational well-being and wealth: Māori businesses and an ethic of care. Journal of Business Ethics, 98, 153-169.

Spiller, C., Pio, E., Erakovic, L., Henare, M. (2011) Wise Up: Creating organizational wisdom through an ethic of Kaitiakitanga. Journal of Business Ethics, 104(2), 223-235. https://www.jstor.org/stabl e/41476082.

Stewart, G. T. (2020). Māori philosophy: Indigenous thinking from Aotearoa. London: Bloomsbury.

Subramanian, S. (2020). How the face mask became the world's most coveted commodity. The Weekly Guardian. Retrieved from https://www.theguardian.com/world/2020/apr/28/face-masks-covetedcommodity-coronavirus-pandemic.

The Telegraph. (2012, November). https://www.telegraph.co.uk/education/primaryeducation/9677976/ Primary-school-children-punished-for-not-speaking-Welsh.html.

Tombs, S., \& Whyte, D. (2015). The corporate criminal. London: Routledge.

Verbos, A. K., Kennedy, D. M., \& Gladstone, J. S. (2011). "Coyote Was Walking. . .”: Management education in Indian Time. Journal of Management Education, 35(1), 51-65. https://doi. org/10.1177/1052562910384368.

Wa Thiong'o, N. (1986). Decolonising the Mind: The Politics of Language in African Literature. Suffolk, UK: James Currey [now Boydell and Brewer].

Weizenbaum, J. (Ed.). (1976). Computer power and human reason: From judgement to calculation. San Fransisco: W. H Freeman and Company.

White, L., Jr. (1971). Cultural climates and technological advances in the middle ages. Viator, 2, 171-201.

Publisher's Note Springer Nature remains neutral with regard to jurisdictional claims in published maps and institutional affiliations. 